\title{
Reclassification in the Libraries of the Great Lakes Colleges Association
}

\begin{abstract}
A comprehensive survey of the reclassification situations in the libraries of nine reputable colleges was made by questionnaire. This summary of the findings shows that approaches to reclassification differ considerably according to institutional financial support and available professional skills. Besides defining the general pattern that library reclassification appears to be taking at this time, the survey also indicates the means by which reclassification is supported financially, an apparent shortage of catalogers experienced in the use of the LC Classification system, and a possible trend toward the further overburdening of cataloging department staffs.
\end{abstract}

T he Great Lakes Colleges Associa. tion, incorporated in 1961 , is composed of twelve liberal arts colleges located in Ohio, Indiana, and Michigan: Albion, Antioch, Denison, DePauw, Earlham, Hope, Kalamazoo, Kenyon, Ohio Wesleyan, Oberlin, Wabash, and Wooster. The association is probably best known for its program in international education under which its students study in certain foreign universities and receive transferable academic credits for their work. Until recently, the program has been mainly concerned with non-Western areas: the Far East and Latin America. The special language programs necessary for-such study-Chinese, Hindi, Japanese, and Portuguese, in addition to the usual ones-are available at designated home campuses. There are other cooperative programs in the humanities, urban studies, social and natural sciences, and there is a sharing of ideas

Mr. Gaines is Reclassification Director in the Antioch College Library, Yellow Springs, Ohio. among the schools' admissions personnel, business officers, and librarians.

Communication among the GLCA libraries has been good from the start and has been aided by the GLCA Librarians' Newsletter, edited by Richard W. Ryan, librarian at Denison. Reflecting the current interest of academic librarians in the possible adoption of the Library of Congress Classification system, the member libraries sponsored two conferences on reclassification. The first conference was held at Ohio Weselyan University on October 16-17, 1966, and the second at the College of Wooster on April 28-29, 1967. Both were well attended and included a large number of non-GLCA librarians from the tristate area. A survey by questionnaire was made in October 1967 to determine the respective catalogers' experience with the Library of Congress Classification system and to find out, in as much detail as possible, how the various libraries were approaching reclassification. This report is a summary of the findings. Of the twelve GLCA libraries, nine 
TABLE 1

\begin{tabular}{|c|c|c|c|}
\hline & Range & Average & Median \\
\hline $\begin{array}{l}\text { Total library budget } \\
\text { Enrollment . } \\
\text { No. of volumes classed in Dewey } \\
\text { Volumes added last year } \\
\text { No. of professional librarians, including } \\
\text { reclass. directors }\end{array}$ & $\begin{array}{c}\$ 105,(084-217,(0) 33 \\
889-2,540 \\
78,100(\text { est.)-285,000) } \\
4,789-9,189 \\
4-8\end{array}$ & $\begin{array}{r}\$ 169,479 \\
1,756 \\
138,602 \\
6,933\end{array}$ & $\begin{array}{r}\$ 171,0(0) \\
1,806 \\
133,610 \\
7,000\end{array}$ \\
\hline
\end{tabular}

(Albion, Antioch, Denison, DePauw, Earlham, Hope, Ohio Wesleyan, Wabash, and Wooster) have changed to LC since mid-1966. One (Kalamazoo) has been using LC for over thirty years, and two (Kenyon and Oberlin) are presently continuing with Dewey. The latter three have been excluded from this discussion because they are not in the process of changing to $\mathrm{LC}$ and, to a lesser extent, because Oberlin's library is so large (over six hundred and thirtyfive thousand volumes and with a budget of more than $\$ 450,000)$ as to skew the institutional data summarized in Table 1 . All of the figures are for 196768.

Almost within a year's time, all nine libraries had changed to LC. Six of them changed between May 1 and December 27, 1966, and the other three between January 1 and May 10, 1967. All of the libraries which began using LC in 1966 waited from somewhat less than a month to a full year before beginning their various reclassification programs. The average time elapsed was slightly more than four months and the median time three months. Of the three libraries starting in 1967, two began to reclassify at the same time they began using LC for new acquisitions. Reasons for changing to LC, listed according to the frequency with which they were mentioned are: (1) the possibilities for national cataloging, cooperation, and automation; (2) economy; (3) greater suitability of LC; (4) speed; (5) inefficiency of Dewey; and (6) opportunity to re-eval- uate the collection, a reason which is more closely related to reclassification alone. It is interesting that none of the libraries had previously approached their college administrations about a possible change to LC and that their cataloging staffs had never approached their head librarians about the matter.

All nine libraries presented some sort of report or program to their respective college administrations before the change to LC was made. With only two exceptions, those included cost estimates (ranging from $\$ 30,000$ to $\$ 94,000$ ) and time tables (two to ten years) for reclassification. One of the libraries (Antioch) asked for and got an initial appropriation of $\$ 80,000$ to set up a special reclassification unit with its own director to make all possible speed in getting the job done. Another (Albion) was authorized to hire a cataloger experienced in the use of LC Classification to head its project. At least one of the libraries did not ask for a lump sum to take care of reclassification. That library, and probably most of the others, reached some sort of agreement with its administration whereby it got permission to change to LC but at the same time agreed to make no large demands for reclassification funds.

Thus in eight libraries reclassification costs (less the reclassification director's salary, in the case of Albion) are being carried, for the time being at least, by the library's regular operating budget, strengthened by whatever extra funds the librarian can garner. Several libraries 
reported that they are getting various budgetary increments for additional personnel, equipment and supplies, most of which are connected with reclassification. Aside from the two reclassification directors, additional personnel include typists, full or part time nonprofessional assistants, and students-but mostly students. Only in one library (Wooster) is a high-output reclassification project being carried out without additional professional catalogers being hired. In seven of the libraries, the reclassification is being done mostly by the regular cataloging department staff, reinforced to various degrees, in its own office space.

The proposed time tables have been revised according to forthcoming financial support. Two of the libraries have no announced completion date. Three have kept theirs, and one has extended its completion date. The remaining three say that they will probably declare reclassification effectively completed when the most-used Dewey-classed books have been done. It seems likely that others will join that category as the work progresses and the eventual cost becomes apparent. The priorities under which materials are reclassed generally follow the same pattern in all the libraries: (1) continuations, older editions of added titles, and older materials which the catalogers must handle for other reasons; (2) parts of the collection already designated by a letter such as B (Biography) or R (Reference); and
(3) block by block (usually in areas where the shelves are overcrowded or where shifting is the most practical) and/or as books are returned from circulation.

Reclassification speed and costs vary considerably, and unfortunately comparison is made even more difficult because some of the libraries do not keep careful statistics. Apparently reclassification costs are so inextricably bound up in the regular operating budgets of most libraries that it is almost impossible to establish the true unit cost. Not, of course, that the unit cost figure is worth anything without a detailed description of the operation itself-there are just too many factors which affect the cost. All such factors can best be summarized as the library's standard for cataloging. If the library is going to adjust to LC's choice and form of entries and subject headings, do the necessary recataloging, regularize its treatment of series, mend, weed, and initiate binding and replacement, then the cost will be high. If the library retains book pockets and cards, they will add to the cost also. Three of the libraries are just getting started at reclassification, but the output and available unit cost of the other six are given in Table 2.

The nine libraries have a total of $14^{\prime \prime}$ professional catalogers (including the two separately financed reclassification directors), but only four of them have had any previous experience classifying with the LC system. One of the reclassi-

TABLE 2

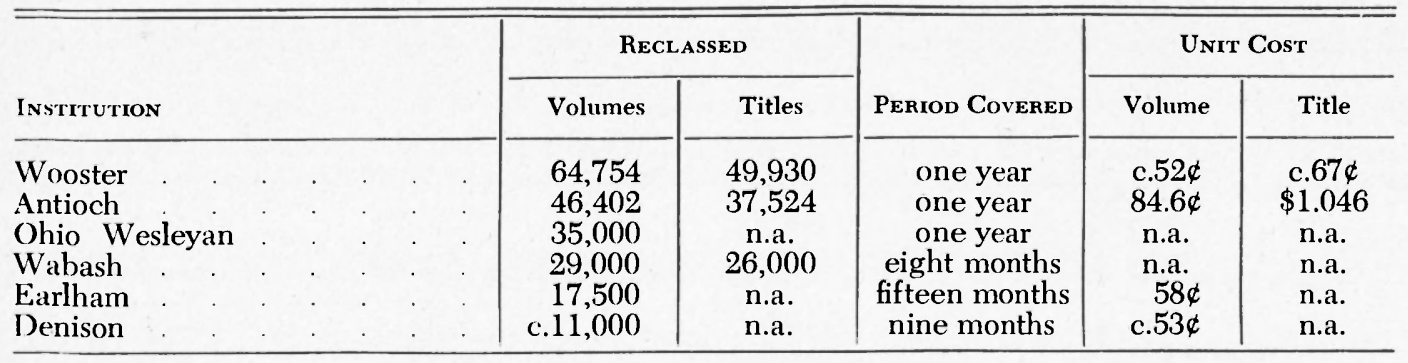


fication directors came to his job after three years of the same work in a small university library. The experience of the other three catalogers is less extensive. One worked for one year classing government documents as separates in a major university library eight years ago. Another recataloged a departmental library in a major university more than twenty years ago, and the third cataloger worked for one year as a cataloger in a small university library twenty-five years ago. Five of the libraries have catalogers with no previous experience in classifying with LC. When the four catalogers with experience in LC are added to the other members of the professional staff who have previously worked or studied in an LC-classed library, the libraries have only sixteen out of a total of 53\% librarians who have some practical familiarity with the system-30 per cent.

As the following practices indicate, the actual standards for cataloging vary considerably within the group of libraries. The extent of recataloging ranges from "whenever necessary" to "very little," but only one library admits that it is doing nothing other than changing the call numbers on the books and cata$\log$ cards. Five say that they are not revamping their series authority files as they reclassify-indeed, several do not even have them. Only one library maintains a clipped file of the quarterly Additions and Changes to the LC schedules, although one other annotates the literature schedules. Except for one library which does not presently have a subscription, the others examine each issue when it arrives and keep it on hand for consultation when necessary. Acceptance of LC's classes PZ 3 and PZ 4 (Fiction in English) also varies. Three of the libraries accept it without alteration, and one always assigns numbers from the national literature classes. The remaining five libraries compromise to various degrees, the most common practice being to use PZ 3 and 4 only when the schedules and the LC Printed Cata$\log$ do not give an official author number in the national literature classes. All of the libraries except one (Antioch) use permanent, self-adhesive paper labels as the major means of changing the call numbers on their catalog cards, a method which seems to have originated with the library at California State College at Long Beach. Whenever new cards are required they are usually run off on the library's Xerox 914, as Antioch does for all its reclassed cards.

The specific difficulties that the catalogers have experienced in the use of LC are, according to the frequency of times mentioned: (1) lack of a comprehensive guide to interpret the schedules and tables; (2) use of the schedules and application of the special tables; (3) the rationale of LC's Cuttering and the arrangement of translations and other editions in relation to the original work: (4) unavailability of literature Cutter numbers for authors classed in PZ 3 and 4; (5) separation of older and newer material caused by LC's revision of the schedules; (6) frequent necessity to do original classification when LC classes a title within a series; and (7) lack of the $K$ (Law) schedule. Strangely enough, three of the libraries reported no specific difficulties using LC. One of those Iibraries has the cataloger with some experience with LC, but the catalogers in the other two libraries have no previous experience with the system.

Most of the advice that the nine Iibraries would give to other libraries considering the change to LC and/or reclassification has to do with reclassification. In the order of frequency, those replies are: (1) investigate and consider all available methods and costs; (2) plan ahead; (3) start slowly; (4) remain flexible; (5) use student help to full advantage; (6) take full advantage 
of labor-saving techniques and materials such as the Se-lin labeler, Xerox, and Avery labels; and (7) do as much processing as possible during the summer when extra labor is available and when the books are not in heavy use.

A few observations might well be made on the implications of the survey findings. Apparently it is accepted practice in many libraries for catalogers to run a more or less modest reclassification program with the time that they have saved by the change to LC. Ultimately that time gain becomes eroded by acquisitions increases and more permanent arrangements for reclassification are necessitated-which means that at some point extra funds will have to be found or the work will bog down. However, even large expenditures cannot always buy the sound standards and consistently good work that experienced and well-trained personnel bring-obviously, there are not enough experienced catalogers to go around. Not all smaller academic libraries, of course, have had particularly high cataloging standards, and in many instances the cataloging personnel are not prepared to cope with burgeoning acquisitions, much less with a reclassification program.

What the individual library must do is to keep careful records of its own procedures and costs and check them regularly against those of comparable institutions. With accumulated data it will be possible to project time and cost figures for various aspects of technical services work, not just for reclassification projects. It would be helpful if the profession were to collect and publish instructional material on the use of the LC Classification system and to standardize and publish the best and most economical procedures dealing with all aspects of technical services work. Without those standards to guide them, many libraries will fail to use this opportunity to establish the firm base that is needed to enable them to meet the demands of the future. The libraries surveyed in this study are comparatively good, sound ones in that most of them have a tradition of adequate financial support and staffing. But what is going on in the academic libraries that are patently under-financed and less competently staffed?

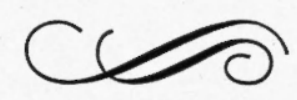

